\title{
Reading the operation of an acid/base-controllable molecular switch by naked eye $\dagger$
}

\author{
Kuang-Wei Cheng, ${ }^{a}$ Chien-Chen Lai, ${ }^{b}$ Pinn-Tsong Chiang ${ }^{a}$ and Sheng-Hsien Chiu* ${ }^{a}$ \\ Received (in Cambridge, UK) 2nd May 2006, Accepted 25th May 2006 \\ First published as an Advance Article on the web 7th June 2006 \\ DOI: 10.1039/b606203b
}

We report a pH-controllable molecular switch whose switching can be monitored by the naked eye; this system involves the formation of a complex between a [2]rotaxane-featuring dibenzylammonium and 4,4'-bipyridinium stations-and a TTF-side-walled molecular clip.

The synthesis of molecular switches and actuators that function through host-guest recognition continues to attract much attention because these systems have potential applicability in mesoscale molecular electronic devices. ${ }^{1}$ Because of the need for reversibility in the operation of these machine-like molecules, chemically controllable molecular switches are generally operated through the sequential addition and removal of electrons, ${ }^{2}$ metal ions, ${ }^{3}$ or protons. ${ }^{4}$ Among these systems, acid/base-controllable molecular switches are relatively simple to design because in general they operate through charge repulsion or hydrogen bonding interactions upon protonation of a receptor in the molecular structure of either the host or guest. ${ }^{4}$ One example of such a system is a [2]rotaxane in which the macrocyclic component can reside at one of two stations. Ideally, the binding affinity of this macrocycle should favor one station exclusively in the "on" state and the other station exclusively in the "off" state - with clear optical output signals in both cases - to ensure that the switching event can be monitored effectively. Most acid/base-controllable molecular switches do not, however, provide significant optical outputs during their switching; rather, their operating states are monitored using NMR spectroscopic techniques. Herein, we describe a $\mathrm{pH}$-controllable molecular switch whose switching can be monitored by the naked eye; this system involves the formation of a complex between a [2]rotaxane - comprising macrocycle $\mathbf{1}$ and a dumbbell featuring dibenzylammonium and 4,4'-bipyridinium stations - and a TTF-side-walled molecular clip. ${ }^{5}$

The dual-use "oxygen-deficient" macrocycle $\mathbf{1}$ is the smallest known macrocycle that is capable of forming relatively strong complexes in solution with dibenzylammonium $\left(\mathrm{DBA}^{+}\right)$and bipyridinium ions. ${ }^{6}$ Because the binding affinity of $\mathbf{1}$ with DBA $\cdot \mathrm{PF}_{6}\left(K_{\mathrm{a}}=200 \pm 30 \mathrm{M}^{-1}\right)$ in $\mathrm{CD}_{3} \mathrm{CN}$ is $c a$. 10-fold higher than that with $N, N^{\prime}$-dimethylbipyridinium bishexafluorophosphate $\left(K_{\mathrm{a}}=26 \pm 2 \mathrm{M}^{-1}\right)$, we suspected that a two-station

${ }^{a}$ Department of Chemistry, National Taiwan University, Taipei, Taiwan, 10617, R.O.C.E-mail: shchiu@ntu.edu.tw; Fax: +886 2 33661677;

Tel: +886233661675

${ }^{b}$ Institute of Molecular Biology, National Chung Hsing University and Department of Medical Genetics, China Medical University Hospital,

Taichung, Taiwan, R.O.C.

$\uparrow$ Electronic supplementary information (ESI) available: Experimental procedures for the preparation of $4-\mathrm{H} \cdot 3 \mathrm{PF}_{6}$ and its characterization data. See DOI: $10.1039 / \mathrm{b} 606203 \mathrm{~b}$ [2]rotaxane comprising these units would operate as an acid/basecontrollable molecular switch. We synthesized (Scheme 1) such a [2]rotaxane through the reaction of the dibenzylammonium ion 2- $\mathrm{H} \cdot \mathrm{PF}_{6}{ }^{7}$ with the monopyridinium salt $3 \cdot \mathrm{PF}_{6}{ }^{8}$ in $\mathrm{CH}_{3} \mathrm{CN}$ in the presence of macrocycle $\mathbf{1}$; the semirotaxane ${ }^{9}$ intermediate $[\mathbf{1} \supset \mathbf{2}-\mathrm{H}]\left[\mathrm{PF}_{6}\right]$ reacted with $\mathbf{3} \cdot \mathrm{PF}_{6}$ to afford the [2]rotaxane $4-\mathrm{H} \cdot 3 \mathrm{PF}_{6}$ in $35 \%$ yield after subsequent ion exchange and purification processes.

The ${ }^{1} \mathrm{H}$ NMR spectrum of rotaxane $4-\mathrm{H} \cdot 3 \mathrm{PF}_{6}$ displays (Fig. 1) significant upfield shifts in the signals of the methylene protons adjacent to the ammonium center relative to those of the free dibenzylammonium ion $\mathbf{2}-\mathrm{H} \cdot \mathrm{PF}_{6}$, which suggests that the macrocyclic unit encircles the $\mathrm{CH}_{2} \mathrm{NH}_{2}{ }^{+} \mathrm{CH}_{2}$ center. ${ }^{10}$ Because the association and dissociation processes of the dibenzylammonium ion and macrocycle $\mathbf{1}$ are slow on the ${ }^{1} \mathrm{H}$ NMR spectroscopic timescale, ${ }^{11}$ if macrocycle $\mathbf{1}$ were to reside anywhere else along the dumbbell-shaped component, i.e., other than on the $\mathrm{NH}_{2}^{+}$center,

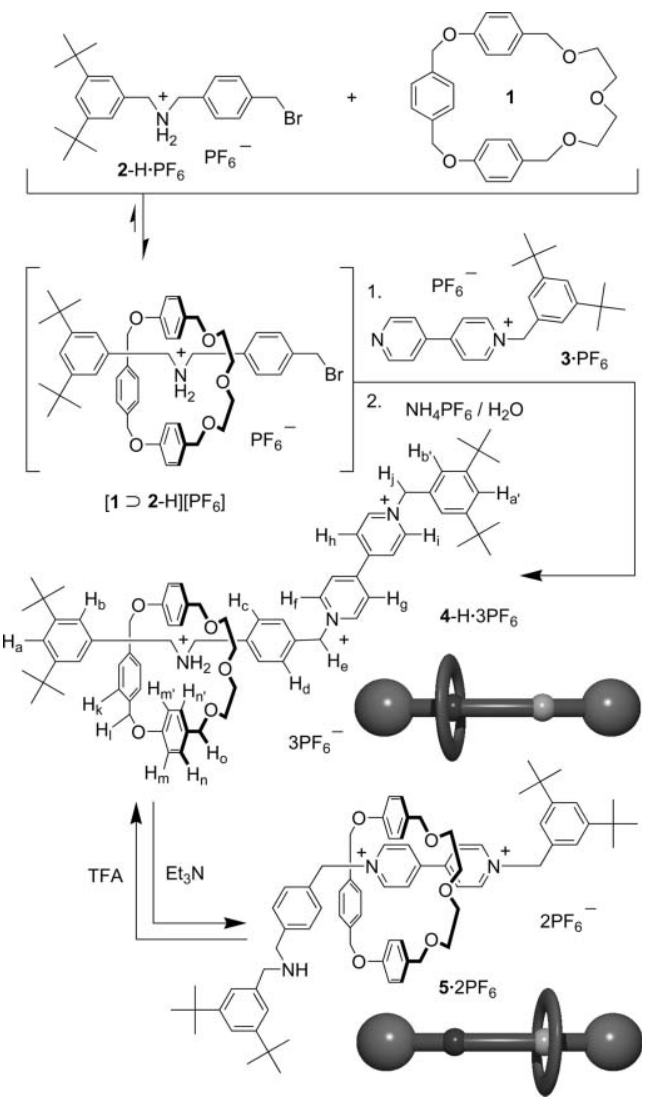

Scheme 1 
we should observe another set of signals representing a second translational isomer; because we do not, it appears that the macrocyclic unit in $4-\mathrm{H} \cdot 3 \mathrm{PF}_{6}$ resides at the $\mathrm{NH}_{2}{ }^{+}$center with good selectivity in $\mathrm{CD}_{3} \mathrm{CN}$ at room temperature. The addition of $\mathrm{Et}_{3} \mathrm{~N}$ to this solution led to deprotonation of the $\mathrm{NH}_{2}{ }^{+}$center, which resulted in the disappearance of the multiplet in the ${ }^{1} \mathrm{H}$ NMR spectrum that we assign to its adjacent methylene protons (Fig. 1b). Meanwhile, the signals for the $\alpha$ and $\beta$ protons of the bipyridinium unit underwent upfield shifts, implying the formation of the [2] rotaxane $\mathbf{5} \cdot 2 \mathrm{PF}_{6}$, in which the macrocyclic unit encircles the bipyridinium unit. Subsequent addition of trifluoroacetic acid (TFA) provided a ${ }^{1} \mathrm{H}$ NMR spectrum (Fig. 1c) similar to that of the original solution of rotaxane $4-\mathrm{H} \cdot 3 \mathrm{PF}_{6}$ (Fig. 1a); this observation implies that the macrocyclic unit had migrated back to the $\mathrm{NH}_{2}{ }^{+}$center to regenerate the original rotaxane $4-\mathrm{H}^{+}$in solution.

Although the switching of the macrocyclic unit from the $\mathrm{NH}_{2}{ }^{+}$ unit to the bipyridinium moiety upon the addition of $\mathrm{Et}_{3} \mathrm{~N}$ did induce a weak charge transfer absorption between the electron-rich phenol ring and the electron-deficient bipyridinium unit - turning the solution from colorless to light yellow - this transformation was not very striking to the naked eye, especially at low concentration. Previously, we demonstrated that the TTF-sidewalled molecular clip 6 forms a complex with $N, N^{\prime}$ dimethylbipyridinium bishexafluorophosphate in $\mathrm{CD}_{3} \mathrm{CN}\left(K_{\mathrm{a}}=\right.$ $\left.5600 \pm 300 \mathrm{M}^{-1}\right) ;^{12}$ this complex displays a green color that arises from a charge transfer absorption between the bipyridinium ion and the TTF units. ${ }^{13}$ Thus, we suspected that mixing the molecular clip 6 with the [2]rotaxane $4-\mathrm{H} \cdot 3 \mathrm{PF}_{6}$ in $\mathrm{CD}_{3} \mathrm{CN}$ would lead to the formation of a [2]rotaxane/molecular clip complex $\left(6 \supset 4-\mathrm{H} \cdot 3 \mathrm{PF}_{6}\right)$ in which the molecular clip coordinates to the free bipyridinium unit to result in a green solution (Scheme 2). The subsequent addition of $\mathrm{Et}_{3} \mathrm{~N}$ to this solution was expected to cause the macrocyclic unit of the [2]rotaxane to compete with the molecular clip for the bipyridinium center; ideally, this process would lead to dissociation of the complex to provide the free [2] rotaxane $5 \cdot 2 \mathrm{PF}_{6}$ and the free molecular clip $\mathbf{6}$ with simultaneous disappearance of the green color.

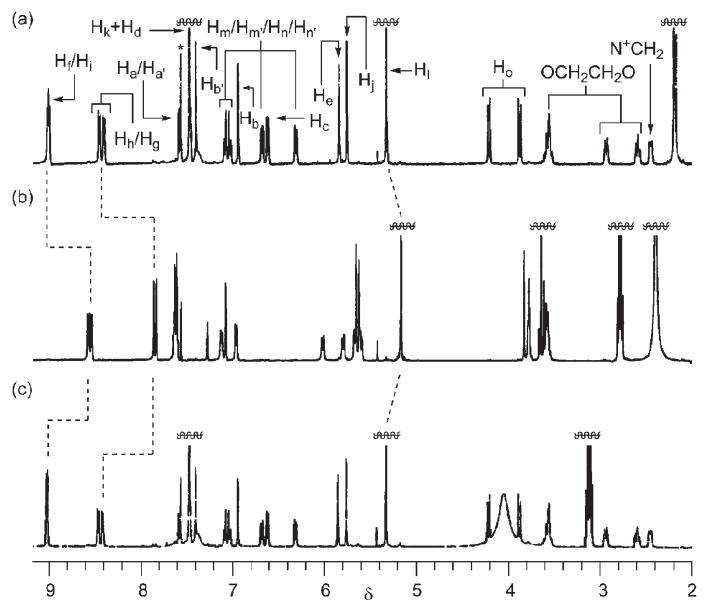

Fig. 1 Partial ${ }^{1} \mathrm{H}$ NMR spectra [ $400 \mathrm{MHz}, \mathrm{CD}_{3} \mathrm{CN} / \mathrm{CDCl}_{3}(5$ : 1), $298 \mathrm{~K}]$ of (a) rotaxane $4-\mathrm{H} \cdot 3 \mathrm{PF}_{6}$, (b) the mixture obtained after adding $\mathrm{Et}_{3} \mathrm{~N}$ ( 2 equiv) to the solution in (a), and (c) the mixture obtained after adding TFA ( 2 equiv) to the solution in (b).

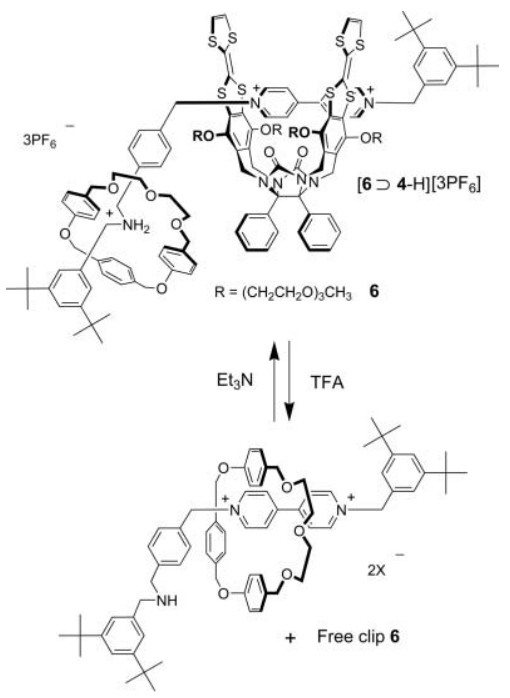

Scheme 2

Gratifyingly, solutions of the colorless [2] rotaxane $4-\mathrm{H} \cdot 3 \mathrm{PF}_{6}$ and the yellow molecular clip formed a green solution upon their mixing (Fig. 2A-a). The UV-Vis spectrum (Fig. 2B-a) of the complex formed between $4-\mathrm{H} \cdot 3 \mathrm{PF}_{6}$ and 6 in $\mathrm{MeCN} \mathrm{CHCl}_{3}(5: 1)$ displays a charge transfer band at $709 \mathrm{~nm}$. The ${ }^{1} \mathrm{H}$ NMR spectrum of this solution indicates (Fig. 3b) that upfield shifts occurred to the signals of the $\beta$-pyridinium protons of the [2]rotaxane and the $\mathrm{PhOCH}_{2}$ protons of the molecular clip; these changes are similar to those that occur after the complexation of molecular clip 6 with $N, N^{\prime}$-dimethylbipyridinium bishexafluorophosphate under similar conditions. ${ }^{11}$ A Job plot based on the signal of the $\mathrm{PhOCH}_{2}$ protons in the ${ }^{1} \mathrm{H}$ NMR spectrum of the molecular clip afforded conclusive evidence (see Supporting Information) for $1: 1$ complexation in $\mathrm{CD}_{3} \mathrm{CN} / \mathrm{CDCl}_{3}(5: 1)$. The electrospray ionization (ESI) mass spectrum recorded on an equimolar mixture of 6 and $4-\mathrm{H} \cdot 3 \mathrm{PF}_{6}$ reveals two peaks at $\mathrm{m} / \mathrm{z} 1374$ and 867 , which correspond to the formation of complexes $\left[\mathbf{6} \supset \mathbf{4}-\mathrm{H} \cdot \mathrm{PF}_{6}\right]^{2+}$ and $[6 \supset 4-H]^{3+}$, respectively. These results suggest the formation of the [2]rotaxane/clip complex $(\mathbf{6} \supset \mathbf{4}-\mathrm{H}) \cdot 3 \mathrm{PF}_{6}$, for which we determined

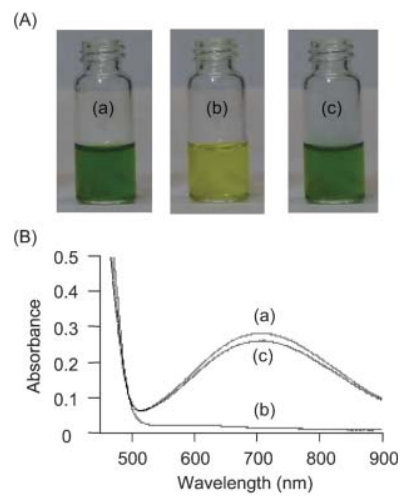

Fig. 2 (A) Photograph depicting the color changes that occur to the solution $\left[\mathrm{MeCN} / \mathrm{CHCl}_{3}(5: 1), 4 \mathrm{mM}, 298 \mathrm{~K}\right]$ during the switching process and (B) the corresponding partial UV-Vis spectra $\left[\mathrm{MeCN} / \mathrm{CHCl}_{3}(5: 1)\right.$, $2 \mathrm{mM}, 298 \mathrm{~K}$ ] of (a) an equimolar mixture of $4-\mathrm{H} \cdot 3 \mathrm{PF}_{6}$ and $\mathbf{6}$, (b) the mixture obtained after adding $\mathrm{Et}_{3} \mathrm{~N}$ (2 equiv) to solution (a), and (c) the mixture obtained after adding TFA (2 equiv) to solution (b). 


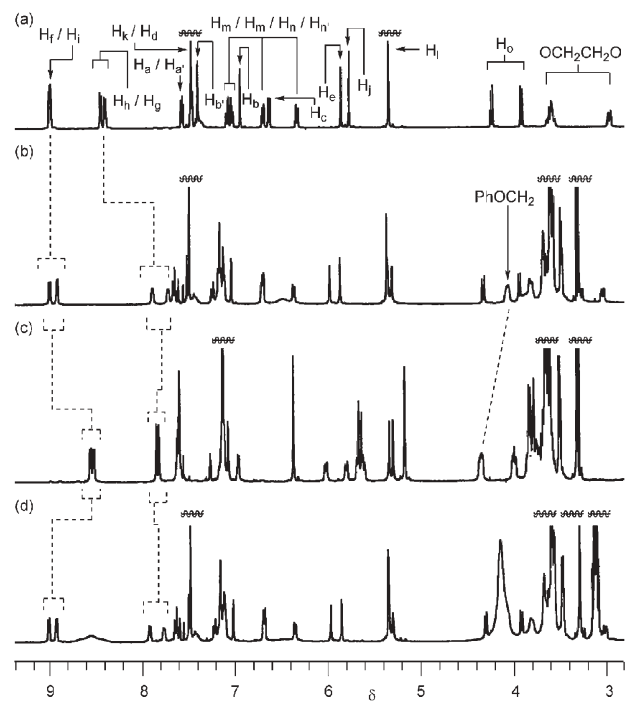

Fig. 3 Partial ${ }^{1} \mathrm{H}$ NMR spectra [ $400 \mathrm{MHz}, \mathrm{CD}_{3} \mathrm{CN} / \mathrm{CDCl}_{3}(5$ : 1), $298 \mathrm{~K}$ ] of (a) rotaxane $4-\mathrm{H}_{3} \cdot 3 \mathrm{PF}_{6}$, (b) an equimolar $(10 \mathrm{mM})$ mixture of rotaxane 4-H.3PF 6 and molecular clip 6, (c) the mixture obtained after adding $\mathrm{Et}_{3} \mathrm{~N}$ (4 equiv) to the solution in (b), and (d) the mixture obtained after adding TFA (4 equiv) to the solution in (c).

the association constant $\left(K_{\mathrm{a}}\right)$ in $\mathrm{CD}_{3} \mathrm{CN} / \mathrm{CDCl}_{3}(5: 1)$ to be $4100 \pm 400 \mathrm{M}^{-1}$, based on a ${ }^{1} \mathrm{H}$ NMR spectroscopic dilution experiment. ${ }^{14}$ The addition of $\mathrm{Et}_{3} \mathrm{~N}$ to the mixture immediately switched the color of the solution back to yellow, with a concomitant substantial decrease in the intensity of the charge transfer absorption in the UV spectrum ( $c f$. Figs. 2A-b and 2B-b); in addition, the corresponding ${ }^{1} \mathrm{H}$ NMR spectrum displays the existence of both the free molecular clip $\mathbf{6}$ and [2] rotaxane $5 \cdot 2 \mathrm{PF}_{6}$ in the solution (Fig. 3c). Thus, the [2]rotaxane/molecular clip complex dissociated upon the addition of $\mathrm{Et}_{3} \mathrm{~N}$, most likely as a result of the macrocyclic unit encircling the bipyridinium station in $5 \cdot 2 \mathrm{PF}_{6}$ to the exclusion of the molecular clip $\mathbf{6}$. Subsequent addition of TFA to this solution restored the charge transfer band at $709 \mathrm{~nm}$ (Fig. 2B-c), immediately switched the color of the solution back to green (Fig. 2A-c), and resulted in a ${ }^{1} \mathrm{H}$ NMR spectrum (Fig. 3d) similar to that of the mixture of only molecular clip 6 and [2]rotaxane $4-\mathrm{H} \cdot 3 \mathrm{PF}_{6}$ (Fig. 3b); this evidence suggests that regeneration of the [2]rotaxane/molecular clip complex occurred in solution upon protonation of the amino center in $5 \cdot 2 \mathrm{PF}_{6}$. Thus, sequential addition of a base and an acid induces migration of the macrocyclic unit of this [2] rotaxane from the $\mathrm{NH}_{2}{ }^{+}$station to the bipyridinium unit and back again, in turn controlling the availability of the bipyridinium station for complexation with the molecular clip $\mathbf{6}$ and resulting in significant color changes that are clearly visible to the naked eye. This process occurs without the need to covalently link chromophore(s) to the macrocyclic and/or dumbbell-shaped components.

We have demonstrated that the presence of a TTF-side-walled molecular clip allows the mechanical motion of a $\mathrm{pH}$-controllable molecular switch to be monitored by the naked eye. We believe that such rotaxane/molecular clip complexes may play roles in functional chemically, electrochemically, and photochemically controllable molecular switches, and possibly in new types of "supramolecular nanovalves"15 that control the flow of important molecules within porous materials.

\section{Notes and references}

1 (a) Molecular Electronics: Science and Technology; A. Aviram and M. Ratner, Eds.; New York Academy of Sciences: New York, 1998; (b) C. P. Collier, G. Mattersteig, E. W. Wong, Y. Luo, K. Beverly, J. Sampaio, F. M. Raymo, J. F. Stoddart and J. R. Heath, Science, 2000, 289, 1172; (c) H. Yu, Y. Luo, K. Beverly, J. F. Stoddart, H.-R. Tseng and J. R. Health, Angew. Chem., Int. Ed., 2003, 42, 5706.

2 (a) A. Mirzoian and A. E. Kaifer, Chem.-Eur. J., 1997, 3, 1052; (b) N. Armaroli, V. Balzani, J.-P. Collin, P. Gaviña, J.-P. Sauvage and B. Ventura, J. Am. Chem. Soc., 1999, 121, 4397; (c) A. Altieri, F. G. Gatti, E. R. Kay, D. A. Leigh, D. Martel, F. Paolucci, A. M. Z. Slawin and J. K. Y. Wong, J. Am. Chem. Soc., 2003, 125, 8644; (d) W. S. Jeon, A. Y. Ziganshina, J. W. Lee, Y. H. Ko, J.-K. Kang, C. Lee and K. Kim, Angew. Chem., Int. Ed., 2003, 42, 4097; (e) H.-R. Tseng, S. A. Vignon, P. C. Celestre, J. Perkins, J. O. Jeppesen, A. Di Fabio, R. Ballardini, M. T. Gandolfi, M. Venturi, V. Balzani and J. F. Stoddart, Chem.-Eur. J., 2004, 10, 155.

3 (a) J.-P. Collin, C. Dietrich-Buchecker, P. Gavina, M. C. JimenezMolero and J.-P. Sauvage, Acc. Chem. Res., 2001, 34, 477; (b) G. Kaiser, T. Jarrosson, S. Otto, Y.-F. Ng, A. D. Bond and J. K. M. Sanders, Angew. Chem., Int. Ed., 2004, 43, 1959; (c) T. Iijima, S. A. Vignon, H.-R. Tseng, T. Jarrosson, J. K. M. Sanders, F. Marchioni, M. Venturi, E. Apostoli, V. Balzani and J. F. Stoddart, Chem.-Eur. J., 2004, 10, 6375.

4 (a) A. M. Elizarov, S.-H. Chiu and J. F. Stoddart, J. Org. Chem., 2002, 67, 9175; (b) J. W. Lee, K. Kim and K. Kim, Chem. Commun., 2001, 1042; (c) M.-V. Martínez-Díaz, N. Spencer and J. F. Stoddart, Angew. Chem., Int. Ed. Engl., 1997, 36, 1904; (d) J. D. Badjic', V. Balzani, A. Credi, S. Silvi and J. F. Stoddart, Science, 2004, 303, 1845; (e) F. Huang, K. A. Switek and H. W. Gibson, Chem. Commun., 2005, 3655 .

5 For glycoluril-based molecular clips, see: (a) A. E. Rowan, J. A. A. W. Elemans and R. J. M. Nolte, Acc. Chem. Res., 1999, 32, 995; (b) J. N. H. Reek, J. A. A. W. Elemans, R. de Gelder, P. T. Beurskens, A. E. Rowan and R. J. M. Nolte, Tetrahedron, 2003, 59, 175; (c) A. Wu, A. Chakraborty, J. C. Fettinger, R. A. Flowers, II and L. Isaacs, Angew. Chem., Int. Ed., 2002, 41, 4028; (d) A. Wu, P. Mukhopadhyay, A. Chakraborty, J. C. Fettinger and L. Isaacs, J. Am. Chem. Soc., 2004, 126, 10035; (e) P.-N. Cheng, P.-T. Chiang and S.-H. Chiu, Chem. Commun., 2005, 1285.

6 P.-N. Cheng, P.-Y. Huang, W.-S. Li, S.-H. Ueng, W.-C. Hung, Y.-H. Liu, C.-C. Lai, S.-M. Peng, I. Chao and S.-H. Chiu, J. Org. Chem., 2006, 71, 2373.

7 S. J. Rowan, S. J. Cantrill, J. F. Stoddart, A. J. P. White and D. J. Williams, Org. Lett., 2000, $2,759$.

8 P. R. Ashton, R. Ballardini, V. Balzani, I. Baxter, A. Credi, M. C. T. Fyfe, M. T. Gandolfi, M. Gomez-Lopez, M.-V. Martínez-Díaz, A. Piersanti, N. Spencer, J. F. Stoddart, M. Venturi, A. J. P. White and D. J. Williams, J. Am. Chem. Soc., 1998, 120, 11932.

9 A semirotaxane has been defined as a pseudorotaxane possessing a stoppering unit at one terminus of the rod-like component. See: (a) J.-P. Collin, P. Gaviña and J.-P. Sauvage, New J. Chem., 1997, 21, 525; (b) C. Seel, A. H. Parham, O. Safarowsky, G. M. Hübner and F. Vögtle, J. Org. Chem., 1999, 64, 7236.

10 P.-N. Cheng, W.-C. Hung and S.-H. Chiu, Tetrahedron Lett., 2005, 46, 4239.

11 (a) P. R. Ashton, P. J. Campbell, E. J. T. Chrystal, P. T. Glink, S. Menzer, D. Philp, N. Spencer, J. F. Stoddart, P. A. Tasker and D. J. Williams, Angew. Chem., Int. Ed. Engl., 1995, 34, 1865; (b) P. R. Ashton, E. J. T. Chrystal, P. T. Glink, S. Menzer, C. Schiavo, N. Spencer, J. F. Stoddart, P. A. Tasker, A. J. P. White and D. J. Williams, Chem.-Eur. J., 1996, 2, 709.

12 P.-T. Chiang, P.-N. Cheng, C.-F. Lin, Y.-H. Liu, C.-C. Lai, S.-M. Peng and S.-H. Chiu, Chem.-Eur. J., 2006, 12, 865.

13 The molecules formed between a tetracationic cyclophane and a threaded TTF motif also display a green color; see: (a) B. W. Laursen, S. Nygaard, J. O. Jeppesen and J. F. Stoddart, Org. Lett., 2004, 6, 4167; (b) W.-Q. Deng, A. H. Flood, J. F. Stoddart and W. A. Goddard, III, J. Am. Chem. Soc., 2005, 127, 15994.

14 K. A. Connors, Binding Constants; Wiley: New York, 1987.

15 (a) R. Hernandez, H.-R. Tseng, J. W. Wong, J. F. Stoddart and J. I. Zink, J. Am. Chem. Soc., 2004, 126, 3370; (b) T. D. Nguyen, H.-R. Tseng, P. C. Celestre, A. H. Flood, Y. Liu, J. F. Stoddart and J. I. Zink, Proc. Natl. Acad. Sci. U. S. A., 2005, 102, 10029. 